\title{
Pancreatic Society of Great Britain and Ireland
}

\author{
The Ninth Annual Meeting of the Pancreatic Society of Great Britain and Ireland was held at the Clinical \\ Lecture Theatre, Manchester Royal Infirmary on 16 November 1984, under the Presidency of Dr Martin \\ Sarner. Abstracts of the papers presented at the meeting are printed below.
}

\section{Cholangitis and acute pancreatitis.}

M J MCMAHON, A D MAYER, M G SHEARER, A P CORFIELD, M J COOPER, C W IMRIE, AND R C N WILliamson (Departments of Surgery, General Infirmary, Leeds, Royal Infirmary, Glasgow, and Royal Infirmary, Bristol) In a prospective study of acute pancreatitis (AP), seven $(1.5 \%)$ of 439 patients developed acute cholangitis. Three of the seven died, cholangitis accounting for $7 \%$ of deaths in the series.

There were four women and three men with a median age of 73 years. The AP was mild in each case, and initial progress uneventful. Clinical deterioration characterised by pyrexia, jaundice, rigors and hypotension occurred two to eight days after admission. Four patients were treated conservatively (three deaths) and three by operation (no deaths). At laparotomy or autopsy, there was evidence of cholangitis and an oedematous or normal pancreas.

At the time of admission, patients who developed cholangitis had high levels of bilirubin (mean $73 \mu \mathrm{mol} / 1$ ) and alkaline phosphatase (mean 298 IU/l) compared with other patients with gall stone AP (mean bilirubin $43 \mu \mathrm{mol} / \mathrm{l}$; mean alkaline phosphatase $181 \mathrm{IU} / \mathrm{l})$. The onset of clinical features of cholangitis was associated with a rise in amylase (four patients), bilirubin (five patients), alkaline phosphatase (six patients) and leukocyte count (six patients), all of which normalised progressively in uncomplicated gall stone AP.

Acute cholangitis is a serious complication that can arise in patients with mild AP. Rapid diagnosis and aggressive treatment appear necessary.

Endoscopic retrograde cholangiopancreatography and sphincterotomy in the management of acute pancreatitis

J P NEOPTOLEMOS, N D SLATER, N LONDON, D L CARR-LOCKE, AND D P FOSSARD (Departments of Surgery and Gastroenterology, Leicester Royal Infirmary, Leicester) ERCP may offer an important method of detecting common bile duct (CBD) stones during acute pancreatitis (AP). Endoscopic sphincterotomy (ES) is an alternative to emergency surgery for AP due to gall stones (GS) which has a high mortality in some series. Two previous studies of ES in AP did not fully assess the severity of the attacks. ${ }^{12}$ In this study 38 patients underwent ERCP during the same hospital admission for AP, severity was graded (Glasgow criteria) and biochemical tests performed to assess prediction of CBD stones.

ERCP was performed in 11 patients at one to three days after admission (urgent) and in 27 patients at five to 33 days (delayed). Twenty five patients had GS of which 11 had severe attacks; two patients without GS also had severe attacks. ES and stone extraction was successful in 12 patients with stones in the CBD and one patient had ES for sludge and pus in the CBD (six of these had severe attacks). After ES one patient developed another attack of AP, a second hyperamylasaemia and a third cholangitis (all transient). One patient with severe AP caused by GS died following urgent ECP (no stones in CBD). Serum biochemical tests in patients with GS which separated those with and without CBD calculi/sludge were $\gamma$-glutamyltranspeptidase $(547 \pm 357 ; 177 \pm 148$ iu/l respectively, $p<0.005)$, alkaline phosphatase $(565 \gamma 433 ; 207 \pm 127 \mathrm{iu} / \mathrm{l}$ respectively, $p<0.02)$ and bilirubin $(86 \pm 55 ; 29 \pm 25 \mu \mathrm{mol} / 1$ respectively, $\mathrm{p}<0.005)$ but not alanine transaminase or amylase (mean \pm SD. Mann-Whitney ranking test)

These preliminary findings indicate that ERCP may be successfully undertaken in patients with AP and that ES may reduce morbidity. Further evaluation of ES is required to determine whether mortality from AP can be reduced.

References

1 Safrany L. Cotton PB. A preliminary report: urgent duodenoscopic sphincterotomy for acute gallstone pancreatitis. Surgery 1981: 89: 424-8.

2 Rosseland AR. Solhaug JH. Early or delaved endoscopic papillotomy in gallstone pancreatitis. Ann Surg 1984: 199: 165-7.
Generation of lysolecithin by enterokinase in trypsinogen, prophospholipase $\mathrm{A}_{2}$, lecithin mixtures, and its relevance to the pathogenesis of acute necrotising pancreatitis

T R TERRY, D A W GRANT, AND J HERMONTAYLOR (Department of Surgery, $S t$ George's Hospital Medical School, London) Acute necrotising pancreatitis may occur after the reflux into the pancreatic duct system of bile containing catalytically active enterokinase. ' The introduction of this enzyme into mixtures of bile salt and lecithin with trypsinogen and prophospholipase $A_{2}$ within the pancreas could initiate a pathogenetic cascade that would rapidly generate concentrations of lysolecithin that are lytic for pancreatic acinar cells.$_{2} \mathrm{~A}$ model of this cascade, namely enterokinase $\rightarrow$ trypsinogen $\rightarrow$ prophospholipase $a^{2} \rightarrow$ lecithin generating trypsin, phospholipase $\mathrm{A}_{2}$ and lysolecithin respectively was studied in vitro using a novel phospholipase $\mathrm{A}_{2}$ assay which detects the appearance of 1-14C lysolecithin after separation of di 1-14C lecithin by thin layer chromatography. Results have shown that $(A)$ the rate of trypsinogen activation by enterokinase is progressively reduced with increasing concentration of bile salt $\left(\mathrm{Na}^{+}\right.$ glycodeoxycholate) in the incubate, (B) the stability of active phospholipase $\mathrm{A}_{2}$ in reaction mixtures was critically dependent on the trypsin/prophospholipase $\mathrm{A}_{2}$ molar ratio, (C) the principal rate limiting factor in lysolecithin production from the entire cascade is the bile salt/lecithin molar ratio; at $4 \mathrm{mmol} / / \mathrm{CA}^{2+}$, peak phospholipase $\mathrm{A}_{2}$ activity occurred with a ratio of 1.25 to 1 and (D) a mixture of presumptive pathophysiological concentrations of enterokinase $(100 \mathrm{ng} / \mathrm{ml})$, trypsinogen $(14$ $\mathrm{mg} / \mathrm{ml})$, prophospholipase $\mathrm{A}_{2}(1 \mathrm{mg} / \mathrm{ml})$. lecithin $(2.5 \mathrm{mg} / \mathrm{ml})$ and $4 \mathrm{mmol} / \mathrm{l} \mathrm{Na}^{+}$ glycodeoxycholate, results in concentrations of lysolecithin $>0.2 \mathrm{mg} / \mathrm{ml}$ within five minutes. These results suggest that an admixture of bile containing enterokinase with pancreatic juice in vivo would result in the rapid production of 
lysolecithin in concentrations that are lytic for pancreatic acinar cells.

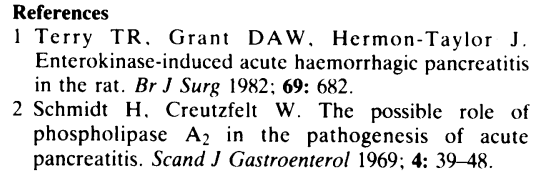
Enterokinase-induced acute haemorrhagic pancreatitis in the rat. Br J Surg 1982; 69: 682.

2 Schmidt $H$. Creutzfelt $W$. The possible role of phospholipase $A_{2}$ in the pathogenesis of acute pancreatitis. Scand J Gastroenterol 1969; 4: 39-48.

Bile, infection and pancreatic duct integrity

C P ARMSTRONG, T V TAYLOR, AND H B TORRANCE (Department of Surgical Gastroenterology, Manchester Royal Infirmary, Manchester) Bile reflux into the pancreatic duct with damage to the pancreatic duct mucosal barrier (PMB) may initiate acute gall stone pancreatitis (AGP). We have investigated the effects of bile and infection on the PMB using the rat bile-pancreatic duct (BPD).

The BPD was perfused at low pressure at $100 \mu \mathrm{l} / \mathrm{h}$ with a standard solution (SPS) $\left[\mathrm{Na}^{+} 150, \mathrm{HCO}_{3}-120, \mathrm{Cl}-30 \mathrm{mmol} / \mathrm{l}\right]-$ period 1 , with the test solution - period 2 and finally with SPS again - period 3. The difference in ionic flux $(\mu \mathrm{mol} / \mathrm{cm} / \mathrm{h})$ of $\mathrm{Cl}-(\Delta \mathrm{JC} 1)$ and $\mathrm{HCO}_{3}-\left(\Delta \mathrm{JHCO}_{3}\right)$ and transductal potential difference $(\Delta \mathrm{pD}$, $\mathrm{mV}$ ) between periods 3 and 1 was calculated. Damage to the PMB was indicated by an increase in ion flux and a change in $\mathrm{pD}$, with electron microscopic (em) confirmation. The test solutions were (A) SPS (control), (B) SPS $+E$ coli,(C) sterile human bile, (D) infected human bile $(E$ Coli), ( $\mathrm{N}=10$ for each).

The PMB remained stable after perfusion with both control (A) and $E$ coli (B) solutions (Table). Sterile bile (C) increased ion flux and altered $\mathrm{pD}$ with epithelial flattening and loss of microvilli on em. Infected bile (D) was more toxic than sterile bile (C) with a striking increase in ion flux and marked change in $\mathrm{pD}$; on em there was pronounced epithelial disruption and cell shedding.

Thus sterile bile produced moderate damage to pancreatic duct integrity. This damage was significantly increased when

Table Change in ion flux (Mean $\pm S D$ )

\begin{tabular}{|c|c|c|c|c|}
\hline Group & $(\mathrm{No})$ & $\triangle J C I$ & $\triangle \mathrm{JHCO}_{3}$ & $\Delta p D$ \\
\hline A & (10) & $+0 \cdot 10 \pm 0 \cdot 05$ & $-0.07 \pm 0.03$ & $+0 \cdot 1 \pm 0 \cdot 01$ \\
\hline B & (10) & $-0.02 \pm 0 \cdot 01$ & $-0 \cdot 06 \pm 0 \cdot 02$ & $+0 \cdot 1 \pm 0.03$ \\
\hline $\mathrm{C}$ & (10) & $+0.43 \pm 0 \cdot 10^{*}$ & $-0.33 \pm 0.09^{*}$ & $+0.4 \pm 0.08^{*}$ \\
\hline D & (10) & $+1 \cdot 29 \pm 0 \cdot 20 \dagger$ & $-1 \cdot 30 \pm 0 \cdot 12 \dagger$ & $+0.7 \pm 0.09+$ \\
\hline
\end{tabular}

the bile was infected. The presence of infection in bile may have an important role in the pathogenesis of AGP.

\section{Peritoneal fluid pool in acute pancreatitis - an enzyme sump?}

A D MAYER AND M J MCMAHON (The General Infirmary, Leeds) It has been suggested that transperitoneal absorption is the most important pathway for transfer of enzymes from pancreas to plasma in acute pancreatitis. ${ }^{1}$ Many patients with mild pancreatitis, however, display high concentrations of plasma amylase but little or no ascitic fluid.

In order to investigate this paradox, 16 anaesthetised dogs with experimental pancreatitis were divided into four equal groups: (1) abdominal lymph was drained via a thoracic duct fistula; (2) the pancreas was enveloped in a polythene bag and pancreatic exudate was continuously re moved using a sump drain; (3) both lymph and exudate were drained; (4) neither lymph nor exudate were drained. Blood, lymph and exudate samples were taken at 30 minute intervals and all free peritoneal fluid was collected at the end of the experiment.

Six hour accumulation of amylase (IU) [median value and interquartile range].

\begin{tabular}{|c|c|c|}
\hline & $\begin{array}{l}\text { Exudate drained } \\
\qquad(n=8)\end{array}$ & $\begin{array}{l}\text { Exudate not drained } \\
\qquad(\mathrm{n}=8)\end{array}$ \\
\hline \multicolumn{3}{|c|}{ Pancreatic exudate $8410[7368-20733]$} \\
\hline Free peritoneal fluid & id $555[103-890]$ & $11039[8789-17495]$ \\
\hline Abdominal lymph & $571[319-972]$ & $536[252-862]$ \\
\hline
\end{tabular}

Most of the enzyme released from the gland accumulated in the pancreatic exudate, but removal of the exudate did not influence either lymph or plasma enzyme levels. There was an early rise in plasma amylase in all animals, probably due to pancreatic venous absorption. Thereafter, thoracic duct drainage significantly reduced plasma enzyme concentrations.

The results suggest that the peritoneal cavity forms a sump for pancreatic enzymes but that transperitoneal absorption does not make a major contribution to plasma enzyme levels in acute pancreatitis.

Reference

1 Waterman NG and Walsky RS. Transperitoneal absorption of amylase in experimental pancreatitis Surg Gynecol Obstet 1970; 131: 729-32.

Misplaced pancreatic duct orifice as a cause of recurrent acute pancreatitis
L C CAREY (Department of Surgery, Ohio State University, Columbus, Ohio, USA) Recurrent acute pancreatitis in the absence of alcoholism and gall stones is a frustrating illness for both the patient and the physician. Since 1976,28 patients have been operated upon and found to have a pancreatic duct (Wirsung) entering the duodenum through the fibres of the sphincter of Oddi. There had been recurrent pancreatitis diagnosed of sufficient intensity to require hospitalisation an average of 3.6 times per patient and numerous episodes of abdominal pain of lesser severity. At least two attacks of pancreatitis requiring hospitalisation had occurred in all patients. All known causes of pancreatitis including alcoholism, gall stones, hypercalcaemia, hyperlipidemia, drug reactions, and pancreas divisum were excluded. ERCP showed no ductal abnormality. Twenty five of the patients had previous cholecystectomy eight months to 20 years before operation. The age range of this population was 15-77 years. A sphincteroplasty of the common bile duct and duct of Wirsung has resulted in elimination of attacks of pancreatitis in all of the cases. The period of follow up has been more than three years in nine, more than two years in five, more than one year in six $(71 \%$ more than one year), and less than one year in eight. There have been no deaths. It appears that the entrance of the duct of Wirsung into the duodenum through a separate orifice through the fibres of the sphincter of Oddi causes recurrent acute pancreatitis. It seems likely that the problem is one of intermittent pancreatic duct obstruction. Normal pancreatic duct calibre is attributed to the intermittent nature of the obstruction. The condition is not recognisable by ERCP Enlargement of the orifice of the duct of Wirsung and division of the sphincter of Oddi relieves the recurrent attacks of pancreatitis.

Hyperenzymemia and molecular size distribution of trypsin and elastase 1 in the serum after ERCP and during acute pancreatitis

L BENINI, G BROCCO, F TAGLIARO, R DORIZZI, I VANTINI, A FIORETTA, G ANGELINI, G CAVAllini, AND L A SCURO (Clinica Medica, Università di Verona, Verona, Italy) After ERCP, raised concentrations of pancreatic enzymes are often reported; the question if this represents a subclinical form of pancreatitis being matter of de- 
bate. We have studied in serum the concentrations of trypsin (Trypsik, Scrin), lipase (turbidimetric colipase activated method) and elastase 1 (Riakit, Abbott) at $0,30,120$ minutes and 24 hours after ERCP in 57 patients submitted to the examination for suspected pancreatic disease. An at least two-fold increase of the basal value of trypsin, lipase and elastase 1 (still present after 24 hours in the majority of the cases) was found in 19,15 , and seven patients respectively. The sera of seven of them with an increase of all the three enzymes were submitted to HPLC (Beckman isocratic liquid chromatograph fitted with TSK SW 3000 column) and trypsin and elastase 1 measured in the eluate; the same study was performed in the sera coming from six patients with acute pancreatitis (three oedematous, three necrohaemorrhagic) sampled during the second week from the onset of the disease. Before ERCP trypsin was mainly detected in the fraction corresponding to the free state, whereas elastase 1 in two peaks corresponding to the MW of alpha 1 antitrypsin and to MW of $250000-400000$; after ERCP, a progressive reduction in the elastase 1 peak of higher MW was found, minor peaks appearing in fractions where the free enzyme was expected $(20000$ $50000)$ or in peaks of intermediate MW between alpha 1 antitrypsin and the free form $(50000-80000)$ where interalpha antitrypsin is expected. Trypsin profile, on the other hand, remained almost unchanged. In the six patients with acute pancreatitis elastase 1 was detectable mainly in the fraction where the alpha 1 antitrypsin is expected and trypsin mainly in its free form.

In conclusion, these data seem to suggest that ERCP can cause, in a certain percentage of the patients, an hyperenzymemia often lasting more than 24 hours which, for the changing pattern of inhibitors involved, could represent an acute pancreatic damage. Further studies in the early phases of acute pancreatitis are needed to detect if a similar pattern of serum proteases binding is present.

\section{Hyperamylasaemia and pancreatic in- flammation after ERCP}

A P CORFIELD, M J COOPER, M H THOMPSON, R A MOUNTFORD, J T WHICHER, AND R C N WILliamson (Department of Surgery, Bristol Royal Infirmary, Bristol) Acute pancreatitis complicates endoscopic retrograde cholangiopancreatography
(MRCP) in one to two per cent of cases but transient hyperamylasaemia is much more frequently encountered. To assess the clinical significance of this and its relation to pancreatic inflammation we have prospectively assayed serum amylase, immunoreactive trypsin, amyloid A protein (an acute phase reactant) and leucocyte count pre ERCP and at three, six and 20 hours after the procedure. Fifty eight ERCPs were performed on 56 consecutive patients ( 33 women: 23 men. median age 67 years, range 20-87). Pancreatograms were obtained in 43 cases, the common bile duct alone was cannulated in 14 and there was one failed cannulation. Post ERCP hyperamylasaemia $(>600 \mathrm{iul} / \mathrm{l} \mathrm{nr} 0-300)$ was found in two of $14(14 \%)$ cholangiograms. 11 of $30(47 \%)$ pancreatic ductograms and 12 of $13(92 \%)$ cases with parenchymal opacification. Serum trypsin $(>800 \mathrm{ng} / \mathrm{ml}$ nr $140 \cdot 400)$ was present in 29.48 and $90 \%$; amyloid $\mathrm{A}$ was raised to $>$ twice pre ERCP levels in 14,25 and $54 \%$; a rise in leucocyte count $>2 \times 10^{9} / 1$ was observed in 50,30 and $62 \%$. Maximum rises occurred at six hours post-ERCP for amylase, trypsin and leucocyte count and at 20 hours for amyloid A. No patient's course was complicated by clinical symptoms or signs of acute pancreatitis.

We conclude that (a) hyperamylasaemia is a common (49\%) sequel of ERCP; (b) this hyperamylasaemia is associated with raised serum concentrations of amyloid $A$, leucocyte count and particularly immunoreactive trypsin; (c) these findings indicate a sub-clinical acute inflammation of the pancreas and (d) this inflammation is related to the degree of parenchymal opacification during pancreatography.

Clinical and biochemical monitoring for evidence of acute pancreatitis (AP) after ERCP ( \pm sphincterotomy)

C P BROWN, ROSALIND CAMPBELL, S OATES, AND C W IMRIE (Departments of Surgery and Biochemistry, Royal Infirmary, Glasgow) The aim of this study was to determine which test(s) proved most valuable in detecting the development of acute pancreatitis after ERCP ( \pm sphincterotomy). Close clinical and biochemical monitoring of a consecutive group of 41 patients was performed, only five of whom had clinical signs of AP after the procedure. Serum and urine samples were taken before, within a few hours of ERCP and repeated next day. Serum amylase, lipase and iso-amylase were measured together with urinary amylase and creatinine. Twenty seven patients $(66 \%)$ showed no post ERCP rise in serum amylase $>400 \mu / l$, and a further nine patients $(22 \%)$ had levels of $400-700 \mu /$. Five patients had significant immediate post ERCP rises of serum amylase $(>1000$ $\mu / 1)$, and three of these were clinically diagnosed to have acute pancreatitis while two were completely well. Serum lipase results were parallel to serum amylase. The most sensitive single test proved to be the urine amylase estimation, being $>3000 \mu / 1$ in all five patients with clinical signs of AP. Four of the five patients who had clinical evidence of AP had sphincterotomy performed and two had residual CBD stones after this procedure. Serum lipase, total amylase and iso-amylase all reflected the clinical course of illness in these five patients but delay in elevation of these results reduced sensitivity. A combined urine and total serum amylase estimation is the recommended biochemical screen for AP. The Rapignost screening urine 'stix' test may prove useful.

Role of a protease inhibitor in ERCP induced hyperamylasaemia and pancreatitis

G LAFERLA, S GORDON, M WATT, AND W R MURRAY (The Departments of Surgery and Biochemistry, Western Infirmary, Glasgow) Hyperamylasaemia after ERCP has been reported in up to $70 \%$ of patients with a $7 \%$ incidence of acute pancreatitis (AP). ${ }^{1}$ Our experience indicated a higher incidence of AP after pancreatic duct (PD) imaging $(21 \%)$. We have assessed the role of aprotinin, a protease inhibitor, in the prevention of this condition.

Ninety two patients undergoing ERCP were randomised to receive aprotinin or placebo by bolus injection before the procedure. Sequential serum samples (A immediately before; B - immediately after; C-mean four hours after procedure) were obtained to determine amylase profiles. The results were analysed using the Chi test.

The incidence of hyperamylasaemia $(>300 \mathrm{IU} / \mathrm{l})$ in the placebo group was significantly greater when the pancreatic duct was imaged, as compared with imaging of the common bile duct (CBD) only; $(p=0.001$ sample $B, p>0.001$ sample $C)$.

In patients with imaging of the $\mathrm{CBD}$ only, there was no statistical difference in the post-ERCP amylase levels in the apro- 
tinin $v s$ the placebo group. $P D \pm C B D$ imaging in combination with aprotinin resulted in a diminished rise in the serum amylase of sample B as compared with placebo $(p=0 \cdot 05)$. The inhibitory effect on amylase was not in evidence four hours after the procedure. The incidence of pancreatitis after imaging of the PD in those patients receiving aprotinin was less than the placebo group ( $5 \%$ vs $13 \%$ ) but this was not statistically significant $(\mathrm{p}=0 \cdot 5)$.

We conclude that a bolus of aprotinin has a transient inhibitory effect on ERCP induced hyperamylasaemia and further studies are merited.

\footnotetext{
Reference

1 Skude G. Wehlin L. Maruyama T. Ariyama J. Hyperamylasaemia after duodenoscopy and ERCP. Gut $1976 ; 17: 127-32$
}

Pancreatitis after cardiopulmonary bypass operations: is it related to mycoplasma infection?

M J PLAYFORTH, M IONESCU, AND M J MCMAHON (Departments of General and Cardiac Surgery, Leeds General Infirmary, Leeds). Raised titres of complement-fixing antibody (CFA) to Mycoplasma pneumoniae $(\mathrm{Mp})$ are found in $30 \%$ of patients after acute pancreatitis. ${ }^{12}$ After cardiopulmonary bypass operations both pancreatitis and raised titres of CFA have been described. ${ }^{34}$

We therefore studied the incidence of hyperamylasaemia and CFA to Mp after cardiopulmonary bypass operations in 52 consecutive patients. Levels of plasma and urine amylase and plasma isoamylase were assayed, and the amylase to creatinine clearance ratio (ACCR) was calculated before, and one, two and 10 days after, operation. CFA to $\mathrm{Mp}$ was estimated before operation and 10 days later. No patient developed clinical evidence of acute pancreatitis, but the serum amylase rose above 180 Somogyi units per $100 \mathrm{ml}$ in nine patients. In five patients $\mathrm{P}_{3}$ isoenzyme was present, the total amylase reaching 874 units per $100 \mathrm{ml}$ in one of them. The remaining four patients displayed a salivary pattern of hyperamylasaemia. Eight of the 52 patients became hypotensive enough to require inotropic support, and in three of them $\mathrm{P}_{3}$ was demonstrated in serum. ACCR was raised in 26 patients but was not related to hyperamylasaemia or hypotension. A four-fold rise in CFA to Mp was seen in seven patients, one having hyperamylasaemia but no $\mathrm{P}_{3}$.
Subclinical pancreatitis, indicated by the presence of $\mathrm{P}_{3}$ isoamylase, was associated with hypotension, but not related to rises in CFA to Mp or to changes in ACCR.

\section{References}

1 Leinikki P. Panozar P. Tykka H. Antibody response in patients with acute pancreatitis to Mycoplasma pneumoniae. Scand J Gastroenterol 1973; 8: 631-5.

2 Freeman R, McMahon MJ. Acute pancreatitis and serological evidence of infection with Mycoplasma pneumoniae. Gut 1978; 19: 367-70.

3 Feiner H. Pancreatitis after cardiac surgery. A morphological study. Am J Surg 1976; 131: 684-8.

4 Freeman R, King B, Hambling MH. Infection with Mycoplasma pneumoniae. J Thorac and Cardiovasc Surg 1973; 66: 642-4.

How does dietary fat get into solution? Two new phases in ultracentrifuged chyme

D FINE, C BROWN, S SUTTON, T C NORTHFIELD (Departments of Medicine and Biochemistry, St George's Hospital Medical School, London) It is conventional wisdom that ultracentrifuged chyme displays three phases: oil, 'micellar' and precipitate. ${ }^{1}$ Fat absorption is believed to occur from the 'micellar' phase. The postprandial jejunal chyme from each of six normal subjects was lipase-inactivated before ultracentrifugation overnight. Phases were separated by tube-slicer. Lipids were extracted by partitioning, and fatty acids (FA) measured colourmetrically. Careful naked eye examination revealed two extra phases at the top and bottom of the aqueous phase. These were termed upper and lower intermediate phases (UIP and LIP). Physical analysis revealed liquid crystals by polarising microscopy in UIP, and giant liposomes by EM and LIP. Chemical analysis showed that FA concentration was lowest in the 'micellar' phase (mean \pm SEM; 4.0 \pm 1.7 $\mathrm{mM} / \mathrm{l})$. FA concentration in the oil phase was $268 \pm 87 \mathrm{mM} / 1 \quad(\mathrm{p}<0.01)$, in UIP $22 \cdot 3 \pm 15 \cdot 7 \mathrm{mMl} / \mathrm{l}(\mathrm{p}<0 \cdot 05)$, in LIP $11 \cdot 5 \pm 1 \cdot 5 \mathrm{mM} / 1 \quad(\mathrm{p}<0 \cdot 01)$, and in precipitate $173 \pm 73(p>0 \cdot 01)$. Mean FA mass, however, was highest in the 'micellar' phase (44\% of the total phase in sample) because of its large volume. Fatty Acid mass was lower in oil phase $(17 \%$, $\mathrm{p}<0 \cdot 05)$ in UIP $\left(9 \%, \mathrm{p}^{1} 0 \cdot 05\right)$. in LIP $(11 \%, \mathrm{p}<0.01)$, and in precipitate $(19 \%$. $\mathrm{p}<0 \cdot 05)$. Bile acid concentration was similar in UIP to 'micellar' phase $(6.9 \pm 0.9$ $\mathrm{mM} / \mathrm{l})$, but higher in LIP $(13.9 \pm 2.0 \mathrm{mM} / 1$, $\mathrm{p}<0 \cdot 02$ ). Bile acid: total lipid ratios were within the 'micellar' limits, ${ }^{2}$ indicating a true 'micellar' phase. Our conclusions are that two additional phases can be identified in ultracentrifuged jejunal chyme; that UIP contain liquid crystals, and LIP giant lipsomes; and that UIP and LIP both contain FA at a higher concentration than in 'micellar' phase, so that they may have an important physiological role in aqueous solubilisation of lipid.

References

1 Hofmann and Borgstrom. J Clin Invest 1964: 2: 257-77. 2 Mazer et al. Biochemistry 1980; 19: 601-15.

Preoperative ERCP in patients with pancreatic pseudocysts

K G MITCHELL, P B COTTON, AND R C G RUSSELL (Department of Surgery, Western Infirmary, Glasgow, and Departments of Gastroenterology and Surgery, The Middlesex Hospital, London) Between 1976 and 1983, 19 patients (15 men. four women) underwent surgery for pancreatic pseudocysts. All were suspected clinically and confirmed by ultrasound scanning. The aetiology was gall stones (nine), alcohol (five), both (two), unknown (two), and carcinoma (one). Sixteen patients underwent ERCP immediately before surgery. There were no complications. Pancreatograms were obtained in each case and all were abnormal, showing: main duct obstruction (10), duct obstruction with communication to the cyst (two). communication without obstruction (two), or generalised abnormality (two): One patient had pancreas divisum.

The pancreatogram predicted the site of the cyst correctly in $75 \%$.

Four patients had external cyst drainage either before operation or as part of the surgical procedure. Surgery consisted of cyst gastrostomy (nine), distal pancreatectomy (six), total pancreatectomy (one), pancreatico-jejunostomy (one) and cholecystectomy (two). Two patients died postoperatively (one from sepsis the other from carcinoma), 11 patients remain well, six have some residual pain and six are diabetics.

The type of surgery and the results did not appear to be influenced by the integrity of the duct system, suggesting that preoperative ERCP has limited value.

Late follow up of acute pancreatitis (AP) patients

M g SHEARER, J O'NEILl, AND C W IMRIE (Department of Surgery, Glasgow Royal Infirmary) From prospective studies of AP 110 patients (59 men, 51 women; 
overall mean age 41.8 years) attended for review at a mean interval of 50.5 months after their first attack. Review included history, examination and blood samples taken for biochemical and haematological analysis. Seventy four patients $(67 \%)$ had remained well and recurrence free. Isolated recurrences without continued chronic symptoms occurred in $27(24.5 \%)$, while the remaining nine $(8 \%)$ had persistent symptoms. Two from this last group had developed chronic pancreatitis confirmed by ERCP. Biliary tract calculi were responsible for the AP in 53 all of whom underwent surgery at a mean interval of 25 weeks after their AP. Recurrent AP occurred in 13 (nine women, four men) before surgery. Alcohol was the aetiological factor in 40 patients and continued excessive intake resulted in recurrent AP in 13 (all men). Nine patients had other aetiologies (viral infection (four); trauma (three); post-operation (one); carcinoma of the pancreas (one)) and in only eight did the cause remain unknown. Of the 14 who had a pancreatic pseudocyst only four underwent surgical drainage.

This study emphasises the importance of early biliary tract surgery and the necessity of alcohol abstention in the prevention of recurrent AP. There appear to be few residual complications once a patient has recovered from one or two episodes of $\mathrm{AP}$ even when a pseudocyst develops.

Composition and distribution of lipids in chyme from patients with pancreatic steatorrhoea.

D R FINE, C BROWN, P L ZENTLER-MUNRO, K BALA, J C BATTEN, T C NORTHFIELD (St George's Hospital Medical School, London and The Brompton Hospital, London) It is generally believed that in pancreatic steatorrhoea absence of pancreatic lipase prevents hydrolysis of dietary lipid to monoglyceride and fatty acid (MG and FA - the 'solute'), so that there is a lack of soluble lipid for micellar solubilisation by bile acid (the 'solvent'). In order to test this concept, we aspirated postprandial jejunal chyme from six patients with pancreatic steatorrhoea due to cystic fibrosis (CF) and from six healthy subjects (HS) and separated the physical phases by ultracentrifugation. In addition to the micellar (optically clear) phase conventionally described, we identified two novel aqueous phases in chyme from HS, one of which was consistently present in CF. In HS the micellar phase contained FA at a concentraiton of $4.9 \mathrm{mM} / 1$; compared with 1.0 $\mathrm{mM} / \mathrm{l}$ in $\mathrm{CF}$; the two new phases contained FA at concentrations of 20.3 and $11.5 \mathrm{mM} / 1$ in $\mathrm{HS}$, compared with $8.2 \mathrm{mM} / \mathrm{l}$ in $\mathrm{CF}$. Micellar phase MG concentration was also lower in CF than in HS $(0.05$ vs $0.18 \mathrm{mM} / \mathrm{l}$, $\mathrm{p}<0.05)$ but DG and TG concentrations were similar $(0.24$ vs $0.45 \mathrm{mM} / \mathrm{l}$, NS; and 0.15 vs $0.13 \mathrm{mM} / 1$, NS). The preponderance of DG MG in CF is consistent with the action of lingual lipase and we are currently measuring lingual lipase concentrations. The presence of non-polar lipids in CF micellar phase contradicts the conventional requirement for hydrolysis be fore solubilisation. We conclude that: (1) lipolysis in CF is probably due to lingual lipase; (2) the fat it produces may be trapped in a non-micellar phase where it may not be absorbable; (3) the micellar phase itself contains non-polar lipids which also may be non-absorbable. These findings throw new light on the pathogenesis of pancreatic steatorrhoea.

\section{Differentiation between benign and malig- nant pancreatic disease by testosterone assay}

D TAGGART, M G SHEARER, C GRAY, AND C W IMRIE (Departments of Surgery and Steriod Biochemistry, Royal Infirmary, Glasgow) Experimental pancreatic carcinoma has been shown to produce androgen metabolising enzymes and it has been suggested that, in patients, this may result in a low serum testosterone. ${ }^{1}$ We have assessed the androgen profile (testosterone; androstenedione; dehydroepiandrosterone sulphate; oestradiol; sex hormone binding globulin in three groups of patients: 19 with chronic pancreatitis (CP) (15 men, mean age 45 years; four women, mean age 37 years); 18 with histologically proven pancreatic carcinoma (PC) (seven men, mean age 58 years; 11 women, mean age 68 years); 21 with proven gastric carcinoma (GC) (11 men, mean age 66 years; 10 women, mean age 64 years).

Only one man with C.P had a testosterone level below normal (11-36 nmol/l): mean result $23.4 \mathrm{nmol} / \mathrm{l}$. However, two male PC and three male GC patients had testosterone levels above $11 \mathrm{nmol} / \mathrm{l}$. The means (male PC $8.9 \mathrm{nmol} / \mathrm{l}$ : male GC 8.2 $\mathrm{nmol} / \mathrm{l}$ ) were significantly different from the $\mathrm{CP}$ result. (Mann-Whitney test and t-test). The $\mathrm{CP}$ results were higher $(p=<0.05)$ and the GC results $(p=<0.05)$ and $P C$ results $(p=<0 \cdot 1)$ lower than the means for age matched controls.

The female results were not significantly different between the three groups.

In men in whom the differential diagnosis of pancreatic disease is equivocal a low serum testosterone may indicate malignancy but it is not specific for pancreatic carcinoma.

Reference

1 Greenway B. Iqbal MJ. Johnson PJ, Williams R. $\mathrm{Br}$ Med J 1983: 286: 93-5.

Alternative surgical procedures for the management of pancreatic disease

R C G RUSSELL (The Middlesex Hospital, London) The long term results of ablative pancreatic procedures can be marred by the poor functional results following surgery with diarrhoea and disturbance of gastric emptying presenting major management problems in the postoperative period. The pylorus preserving pancreatoduodenectomy has been described as a means of overcoming this disability.

Three patients who have required resection of the head of the pancreas have had a pylorus preserving resection of the head. Each patient required prolonged intravenous feeding (3-5 weeks) postoperatively on account of delayed gastric emptying, but once gastric emptying started the side effects of pancreatic resection appear less at the three month stage.

After experience with four babies (less than one year old) who had a $98 \%$ pancreatectomy for nesidioblastosis, it became apparent that the duodenum would survive after removal of the superior and inferior pancreatoduodenal arteries. Three adults have had a total pancreatectomy with preservation of the duodenum and in two the bile duct without necrosis of the duodenum or the bile duct. The duodenum was slow to empty postoperatively, but within one month of operation oral feeding was resumed with an adequate functional result at three months.

It is suggested that preservation of the pylorus and duodenum should be considered in those patients requiring ablative pancreatic surgery. 